\title{
Low-Temperature Performance of Radiosonde Electric Hygrometer Elements ${ }^{1}$
}

\author{
By Arnold Wexler
}

\begin{abstract}
The performance of radiosonde electric hygrometer elements was investigated in the temperature range from 0 to $-40^{\circ} \mathrm{C}$. It was found that an element indicated relative humidity with an average deviation of \pm 2 .4-percent relative humidity from the average calibration for all of the elements tested. The maximum deviation in indication of any element did not exceed 10.5-percent relative humidity. The lag in response was found to increase markedly with decrease in temperature, to depend upon the magnitude and direction of relative humidity change, and the relative humidity from which the change was made.
\end{abstract}

\section{Introduction}

In the meteorological sounding of the upper atmosphere by means of the radiosonde, the device generally used in this country for humidity measurement is the electric hygrometer developed by Dunmore. ${ }^{2}$ In a radiosonde flight in the temperate zone, temperatures below $0^{\circ} \mathrm{C}$ may be encountered from the ground up during the winter months, whereas during the summer months, freezing temperatures usually exist above 18,000 feet. Since a flight may reach an elevation of 80,000 feet, the greater proportion of the ascent will be at low temperatures. Information on the characteristics of the electric hygrometer at temperatures below $0^{\circ} \mathrm{C}$ is therefore important. Glückauf ${ }^{3}$ has reported both calibration and lag data on the coil type of electric hygrometer at low temperatures. Data at low temperatures on the flat-strip hygrometer element used in radiosondes are very meager. An investigation was therefore undertaken to determine the performance of the flat-strip electric hygrometer at low temperatures.

\section{Description of Hygrometer}

The hygrometer most readily available, and therefore used in this study, was one in current

\footnotetext{
1 This investigation was financially supported by the Bureau of Ships, Department of the Navy.

2 F. W. Dunmore, J. Research NBS 20, 723 (1938) RP1102; F. W. Dunmore J. Research NBS 23, 701 (1939) RP1265; H. Diamond, W. S. Hinman, F. W. Dunmore, and E. G. Lapham, J. Research NBS 25, 327 (1940) RP1329.

3 E. Glückauf, Proc. Phys. Soc. (London) 50, 344 (1947).
}

manufacture. This element, which is a modification of the original Dunmore design, and which is used by the Weather Bureau, Navy, and Army, is made by coating a flat strip of polystyrene base, $4 \mathrm{in}$. long and $9 / 16$ in. wide, with an electrolytic film of lithium chloride dissolved in polyvinyl acetate or polyvinyl chloride, and sputtering tin electrodes on the two long edges. The resistance between the electrodes varies with relative humidity. This resistance, operating in the relaxation oscillator circuit of the radiosonde transmitter, controls the value of the audiofrequency to which the carrier wave is modulated.

\section{Experimental Procedure}

An experimental procedure was adopted that would subject the element as far as practical to conditions simulating those encountered in a radiosonde flight. Standard equipment was employed. A radiosonde was utilized to transmit the response of the element to humidity changes; a radio receiver to detect the intelligence from the radiosonde transmitter; an electronic frequency meter and a recorder to automatically record the data in terms of audio frequency or recorder divisions. One recorder division was equal to $2 \mathrm{c} / \mathrm{s}$.

The temperature circuit of the radiosonde was modified to provide an additional humidity circuit. A sequence switch that automatically changed the transmitted signal from one humidity circuit to the second humidity circuit to a reference 
frequency and back to the first humidity circuit was connected to the radiosonde. The radiosonde was permitted to transmit a signal continuously, the duration of which was 23 sec on one humidity circuit, 22 sec on the other humidity circuit, and 15 sec on the reference frequency, a complete cycle lasting $60 \mathrm{sec}$.

Known humidities at constant temperature were obtained by utilizing the divided flow, low temperature humidity apparatus. ${ }^{4}$ This equipment produced an air atmosphere whose relative humidity, with respect to ice, was known to an accuracy of 3 percent.

The test procedure employed was to insert one or two elements into the test chamber of the humidity apparatus which had been brought to and maintained at a desired temperature. Each element was removed from its sealed vial immediately before test and inserted into the test chamber of the apparatus at as low a relative humidity as could be measured and recorded. The air velocity in the test chamber was adjusted to $525 \mathrm{ft} / \mathrm{min}$. The element was tested with its length vertical and air flowing parallel to the length. The element was subjected in discrete steps of 16.7 percent to increasing values of relative humidity up to 100 percent, and back again to the lowest relative humidity. The change from one value of relative humidity to another took 1 to 2 sec. The element was exposed to a relative humidity long enough for the recorded reading to become constant. A total of 29 elements were used in this investigation.

\section{Data and Results}

The hygrometer was subjected to a humidity calibration at nominal temperatures of $-1^{\circ}$, $-10^{\circ},-20^{\circ},-30^{\circ}$, and $-40^{\circ} \mathrm{C}$. Four or more units were tested at each temperature, and each unit supplied the data for one humidity cycle at one temperature. These data were in terms of relative humidity versus recorder divisions. By applying the standard frequency-resistance relationship for radiosondes, which was found to apply to the radiosonde used, the data were converted into relative humidity versus resistance for each humidity element. These are tabulated in table 1.

${ }^{4}$ A. Wexler, J. Research NBS 40, 479 (1948) RP1894.
The logarithms of the average resistance values from table 1 are plotted against the logarithms of the relative humidity in figure 1 . In this graph only the values of resistance measured for increasing changes of relative humidity, that is, from low relative humidity to 100 percent, were used in order to eliminate hysteresis effects and reduce polarization and exposure effects as much as possible. A family of straight lines was obtained for values of relative humidity of 50 percent and above. Below 50 percent, there is a slight bow in the curves for $-1.1^{\circ}$ and $-9.9^{\circ} \mathrm{C}$, in the direction of higher resistance.

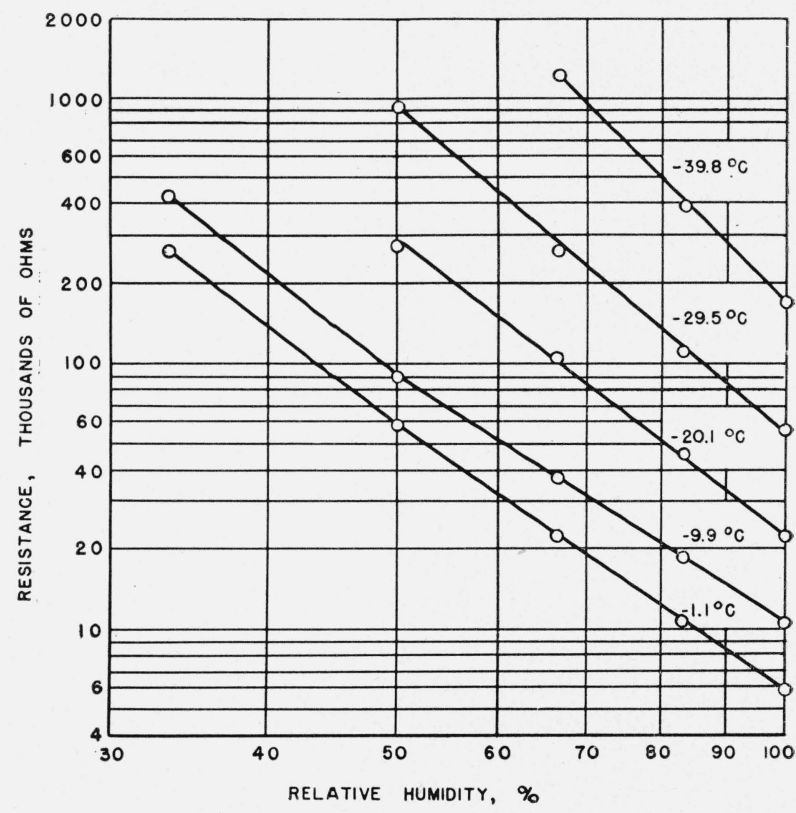

Figure 1. Logarithm of average resistance of the electric hygrometer versus logarithm of relative humidity at low temperatures.

By entering the curves of figure 1 with the resistances for each hygrometer element, as given in table 1, values of indicated relative humidity are obtained. The difference between this indicated relative humidity and the actual relative humidity may be considered a measure of the spread in indication to be expected from individual elements. The indicated relative humidity is the algebraic sum of the actual relative humidity and the difference. These differences are given in table 2 and show that the hygrometer at low temperatures will indicate the relative humidity with an average deviation of \pm 2.4 -percent relative humidity from a mean calibration of all the 
TABLE 1. Low-temperature calibration-relative humidity versus resistance

\begin{tabular}{|c|c|c|c|c|c|c|c|}
\hline $\begin{array}{l}\text { NBS No } \\
\text { Date of run } \\
\text { Temperature, }\end{array}$ & $\begin{array}{c}24 \\
11-17-47 \\
-1.2\end{array}$ & $\begin{array}{c}25 \\
11-17-47 \\
-1.2\end{array}$ & $\begin{array}{c}26 \\
12-1-47 \\
-1.0\end{array}$ & $\begin{array}{c}27 \\
12-1-47 \\
-1.0\end{array}$ & $\begin{array}{c}28 \\
12-1-47 \\
-1.2\end{array}$ & $\begin{array}{c}29 \\
12-1-47 \\
-1.2\end{array}$ & $\begin{array}{c}\text { A verage } \\
-1.1\end{array}$ \\
\hline Relative humidity, \% & \multicolumn{7}{|c|}{ Resistance, ohms } \\
\hline $33.3 \ldots$ & 177,000 & 387,000 & 177,000 & 280,000 & 282,000 & 279,000 & 262,000 \\
\hline 50.0 & 52,300 & 70,500 & 53,000 & 57,500 & ...... & -....... & 58,300 \\
\hline $66.7 \ldots$ & 20,700 & 27,000 & 20,700 & 22,500 & - n- & -...... & 22,700 \\
\hline $83.3 \ldots \ldots \ldots$ & 11,500 & 11,500 & 10,400 & 11,200 & - n. & - n & 11,100 \\
\hline $100.0 \ldots \ldots$ & 6,100 & 6,200 & 5,600 & 6,450 & 6,450 & 6,400 & 6,200 \\
\hline $83.3 \ldots$ & 11,300 & 11,200 & 9,900 & 10,700 & - n. & - n. & 10,800 \\
\hline $66.7 \ldots$ & 20,900 & 27,000 & 20,000 & 23,200 & - n..... & ........ & 22,800 \\
\hline 50.0 & 54,300 & 74,000 & 51,000 & 60,500 & ....... & - . . & 60,000 \\
\hline $33.3 \ldots \ldots$ & 180,000 & 394,000 & 158,000 & 334,000 & 271,000 & 269,000 & 268,000 \\
\hline $\begin{array}{l}\text { NBS No } \\
\text { Date of run } \\
\text { Temperature, }{ }^{\circ} \mathrm{C}\end{array}$ & $\begin{array}{c}1 \\
6-19-47 \\
-9.4\end{array}$ & $\begin{array}{c}2 \\
6-19-47 \\
-9.8\end{array}$ & $\begin{array}{c}3 \\
6-23-47 \\
-19.2\end{array}$ & $\begin{array}{c}4 \\
6-23-47 \\
-10.1\end{array}$ & (n) & (n) & -9.9 \\
\hline 33.3 & 272,000 & 455,000 & 520,000 & 455,000 & - n. & ....... & 425,000 \\
\hline $50.0 \ldots$ & 65,000 & 99,000 & 102,000 & 94,000 & -....... & ........ & 90,200 \\
\hline $66.7 \ldots \ldots$ & 31,200 & 38,000 & 44,000 & 39,900 & - n & - n & 38,300 \\
\hline $83.3 \ldots$ & 17,700 & 18,200 & 21,500 & 19,900 & - n..... & - . & 19,300 \\
\hline 100.0 & 9,800 & 10,300 & 11,900 & 10,800 & - n & - n & 10,500 \\
\hline $83.3 \ldots$ & 14,800 & 17,000 & 20,100 & 18,700 & - n & - n & 17,600 \\
\hline 66.7 & 28,000 & 38,800 & 42,500 & 39,000 & ....... & ....... & 37,300 \\
\hline 50.0 & 61,000 & 103,000 & 101,000 & 93,000 & n...... & - & 89,500 \\
\hline $33.3 \ldots$ & 250,000 & 500,000 & 520,000 & 430,000 & -...... & ....... & 425,000 \\
\hline $\begin{array}{l}\text { NBS No } \\
\text { Date of run } \\
\text { Temperature, }\end{array}$ & $\begin{array}{c}5 \\
6-27-47 \\
-19.7\end{array}$ & $\begin{array}{c}6 \\
6-27-47 \\
-20.1\end{array}$ & $\begin{array}{c}9 \\
10-20-47 \\
-20.4\end{array}$ & $\begin{array}{c}10 \\
10-20-47 \\
-20.1\end{array}$ & no & - n & -20.1 \\
\hline $50.0 \ldots$ & 210,000 & 192,000 & 226,000 & 500,000 & $\ldots \ldots$ & ...... & 282,000 \\
\hline $66.7 \ldots \ldots$ & 94,000 & 91,000 & 93,000 & 149,000 & - n & - n. & 107,000 \\
\hline $83.3 \ldots$ & 42,000 & 42,500 & 43,000 & 57,000 & - n..... & - & 46,100 \\
\hline $100.0 \ldots \ldots$ & 21,200 & 23,200 & 22,900 & 26,200 & (n) & - n & 23,400 \\
\hline $83.3_{-}$ & 40,000 & 41,500 & 56,000 & 53,500 & (n...... & -... & 47,700 \\
\hline $66.7_{\ldots}$ & 93,000 & 88,500 & 156,000 & 139,000 & - n & ....... & 119,000 \\
\hline $50.0 \ldots \ldots$ & 255,000 & 175,000 & 510,000 & 465,000 & - & -...... & 351,000 \\
\hline $\begin{array}{l}\text { NBS No } \\
\text { Date of run } \\
\text { Temperature, }\end{array}$ & $\begin{array}{c}7 \\
6-1-47 \\
-29.7\end{array}$ & $\begin{array}{c}11 \\
10-23-47 \\
-29.4\end{array}$ & $\begin{array}{c}16 \\
10-30-47 \\
-29.2\end{array}$ & $\begin{array}{c}17 \\
10-30-47 \\
-29.7\end{array}$ & (n) & (n- & -29.5 \\
\hline 50.0 & 890,000 & 950,000 & $1,400,000$ & 500,000 & & - & 935,000 \\
\hline 66.7 & 275,000 & 310,000 & 293,000 & 197,000 & - n & -..... & 269,000 \\
\hline $83.3 \ldots$ & 103,000 & 125,000 & 111,000 & 106,000 & -...... & - & 111,000 \\
\hline $100.0 \ldots$ & 51,000 & 60,000 & 54,500 & 52,500 & - n. & (n....... & 54,000 \\
\hline $83.3_{\ldots}$ & 107,000 & 117,000 & 162,000 & 117,000 & & ....... & 126,000 \\
\hline 66.7 & 279,000 & 271,000 & 570,000 & 260,000 & -...... & -...... & 345,000 \\
\hline $50.0 \ldots \ldots$ & 770,000 & 830,000 & $2,000,000$ & 710,000 & - n & ....... & $1,080,000$ \\
\hline $\begin{array}{l}\text { NBS No } \\
\text { Date of run } \\
\text { Temperature, }\end{array}$ & $\begin{array}{c}8 \\
10-7-47 \\
-40.2\end{array}$ & $\begin{array}{c}12 \\
10-28-47 \\
-39.6\end{array}$ & $\begin{array}{c}13 \\
10-28-47 \\
-39.6\end{array}$ & $\begin{array}{c}14 \\
10-28-47 \\
-39.7\end{array}$ & $\begin{array}{l}15 \\
10-28-47 \\
-39.7\end{array}$ & - & -39.8 \\
\hline $66.7 \ldots$ & $1,130,000$ & 930,000 & 880,000 & $1,100,000$ & 930,000 & . . & 994,000 \\
\hline 83.3 & 400,000 & 395,000 & 395,000 & - & -...... & -..... & 397,000 \\
\hline 100.0 & 182,000 & 170,000 & 159,000 & 162,000 & 192,000 & ....... & 173,000 \\
\hline $83.3 \ldots$ & 390,000 & 342,000 & 342,000 & - & - & - & 358,000 \\
\hline $66.7 \ldots \ldots$ & $1,130,000$ & 780,000 & 725,000 & 700,000 & 770,000 & -...... & 821,000 \\
\hline
\end{tabular}


TABLE 2. Difference between indicated and actual relative humidity at low temperature

The indicated relative humidity is the algebraic sum of the actual relative humidity and the difference

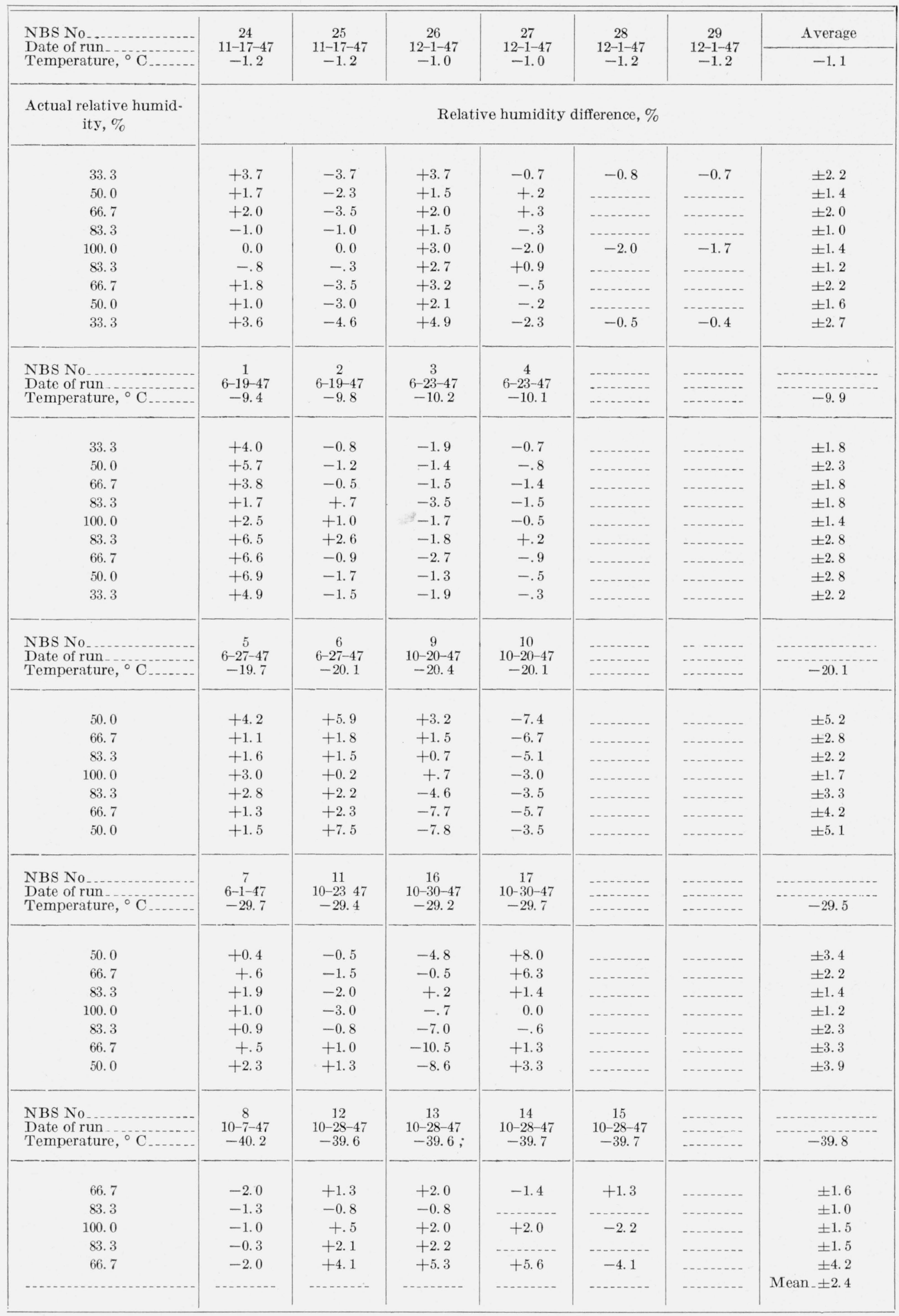


elements tested. There is a tendency for these differences to be larger at the lower humidities and smaller at the higher humidities. The maximum difference did not exceed 10.5-percent relative humidity.

The dependence of the calibration upon temperature is given in tables 1 and 2 and figure 1 . The curves in figure 1 essentially show that the primary effect of temperature is to produce a - parallel displacement of the calibration, a higher humidity being indicated as the temperature is lowered. There also appears to be a small change in slope of calibration curve, but this is a secondary effect.

By interpolating values of resistance for relative humidities of $50,60,80$, and 100 percent from figure 1, converting these into recorder divisions, and plotting them with curves redrawn from the manufacturer's calibration chart for the humidity element, a comparison between the calibration contained in this investigation and the manufacturer's calibration was obtained. This is shown in figure 2 . From $-1^{\circ}$ to $-40^{\circ} \mathrm{C}$, the two calibrations agree within 5 to 7 percent.

In going through a cycle of increasing and then decreasing humidity, the elements, in general, exhibited hysteresis; the indicated relative humidities during the decreasing half of the cycle were sometimes greater and sometimes less than those measured during the increasing half of the cycle. See table 2 for the data. The magnitude of the differences between increasing and decreasing readings in some elements was 1 -percent relative humidity or less; in other units it was observed to be considerably greater. One element (NBS No. 9) changed its indicated relative humidity reading by 11-percent relative humidity in going from an actual relative humidity of 50 to 100 percent and back to 50 percent. Several elements (NBS Nos. 10, 13, 14, 16, and 17) changed their readings by as much as 3 - to 7 -percent relative humidity.

Thelag in response to changes in relative humidity was studied over the range of temperatures from -1 to $-40^{\circ} \mathrm{C}$. The procedure followed was to shift from one relative humidity to another as rapidly as possible ( 1 to $2 \mathrm{sec}$ ), transmitting and recording a humidity signal for 23 sec during 1-min cycles. From the data thus obtained, the lag constant (the time required for 62 percent of the humidity change to occur) was computed.

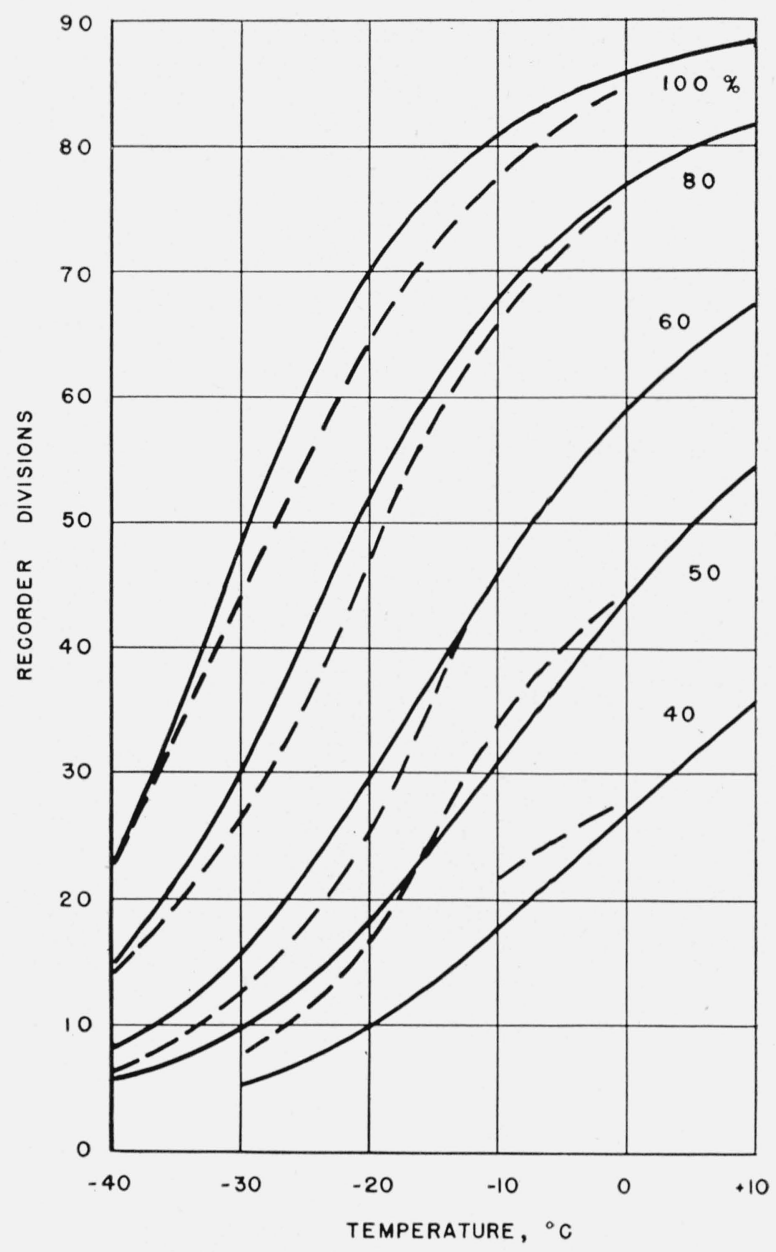

Figure 2. Comparison of NBS and manufacturer's calibration of the electric hygrometer at low temperatures.

Broken line is NBS calibration.

The time response of the hygrometer at low temperatures, although not a simple exponential function, still permitted the calculation of a lag constant with fair approximation. There was variation up to 30 percent in lag constant from element to element when subjected to the same relative humidity change at the same temperature. The lag was found to depend upon temperature, magnitude, and direction of the relative humidity change, and the relative humidity at which the change was made. Figure 3 shows the effect of these variables upon the lag constant. The lag constants used in figure 3 are the averages of two to eight values.

The lag constant was increased by (1) lowering the temperature, (2) increasing the magnitude of the humidity change, and (3) increasing the 


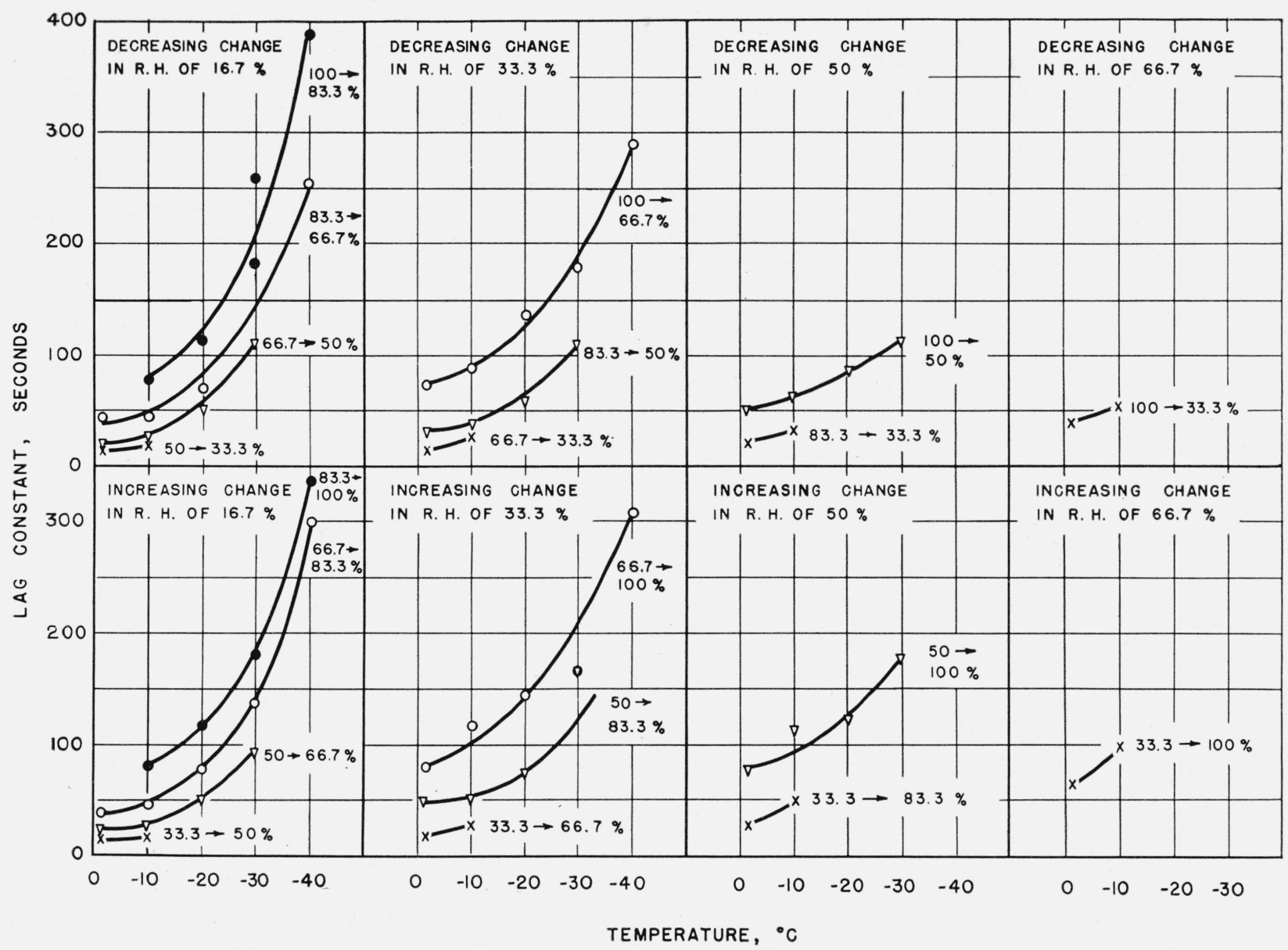

Figure 3. Factors affecting the lag constant.

The magnitude and direction of the change in relative humidity is shown on each curve.

initial value of the relative humidity from which the humidity change is made. For relative humidity changes of 16.7 and 33.3 percent, the lag constant was independent of direction, whereas for changes of 50 and 66.7 percent the lag constant in the increasing humidity direction was larger. The influence of these factors on the lag may also be demonstrated by time response curves for typical elements. In figure 4 is shown the time response of a single element at $-20^{\circ} \mathrm{C}$ to a sudden change in relative humidity of 16.7 percent at various initial relative humidities. The effect of magnitude of humidity change on the time response is shown in figure 5 for a typical element at $-20^{\circ} \mathrm{C}$, in which discrete jumps of $16.7,33.3$, and 50 percent were made from an initial relative humidity of 50 percent. In figures 4 and 5 , the humidity coordinate has been plotted on the basis of percentage change in relative humidity indication. Thus a total change of, say, 16.7-percent relative humidity is plotted on a scale of 100 . An ordinate reading of 25 percent, therefore, represents 25 percent of the humidity change, that is, 25 percent of 16.7-percent or 4.2-percent relative humidity. The effect of temperature on the time responses is given in figure 6 for a relative humidity change of 66.7 to 83.3 percent. Each curve in this figure was obtained on a different unit. 


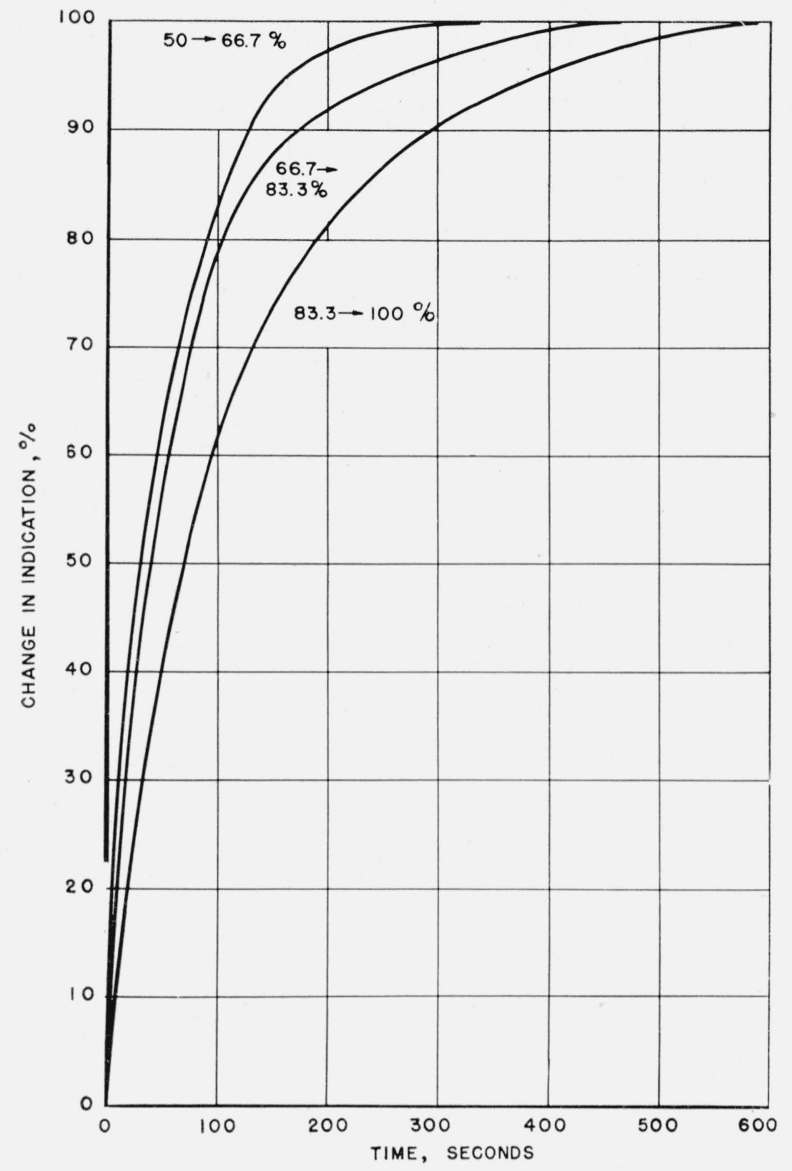

Figure 4. Time response of a typical element at $-20^{\circ} \mathrm{C}$ for a sudden change in relative humidity of 16.7 percent from various initial relative humidities.

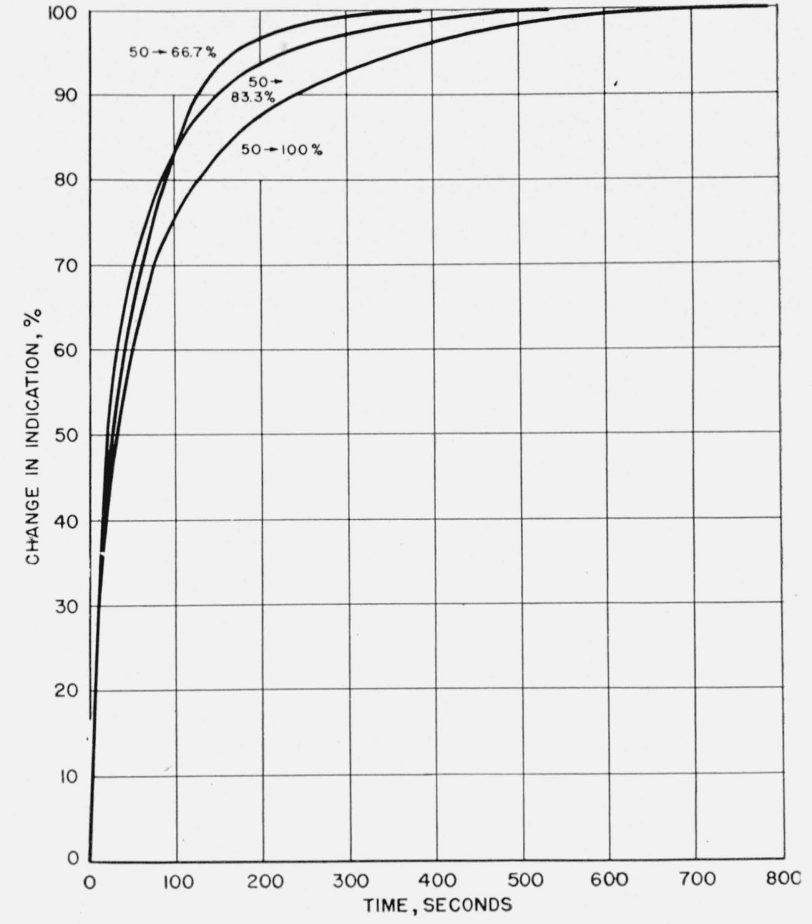

Figure 5. Time response of a typical element at $-20^{\circ} \mathrm{C}$ for discrete changes in relative humidity of 16.7, 33.3, and 50 percent made from an initial relative humidity of 50 percent.

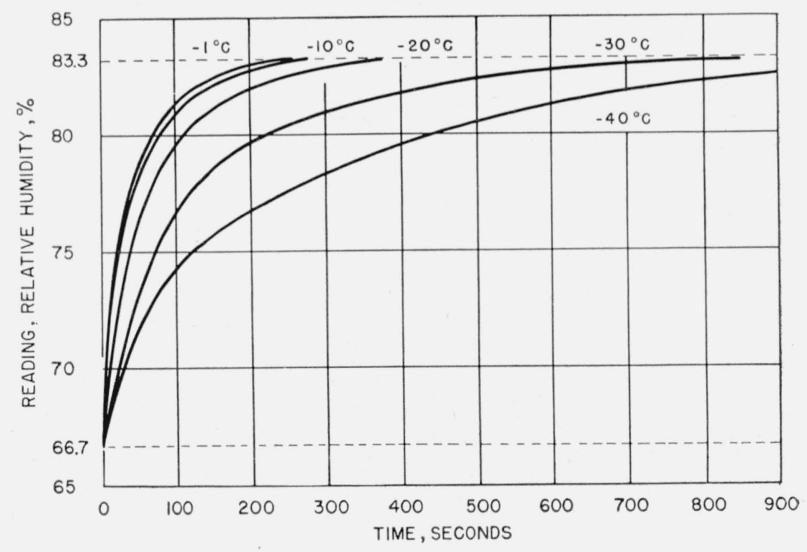

FiguRe 6. Effect of temperature on the time response for a relative humidity change of 66.7 to 83.3 percent. 


\section{Discussion and Summary}

The continued subjection of the electric hygrometer element to the pulsating direct current of the radiosonde circuit has a deleterious effect on its life, primarily because of polarization. Hence in the tests described above, no unit was used more than once or for periods of time exceeding $2 \mathrm{hr}$. Under these conditions, exposure of a unit to a humidity of 100 percent did not appear to harm its performance. In general, the calibra- tion and hysteresis characteristics of the hygrometer are satisfactory, except that the range does not extend to low humidities at the lower temperatures. The high lag and the complicated lag behavior of the hygrometer at low temperatures are its major limitations in radiosonde use. With the rates of balloon ascension now employed $(1,000 \mathrm{ft} / \mathrm{min})$ and the greater rates contemplated for future use, the lag of this hygrometer introduces a questionable factor in the interpretation of the humidity data. 